\title{
Ad hoc planning within distrust and conflict situations: the case of Yaowarat, Bangkok, Thailand
}

\author{
S. Sapu \\ Mahasarakham University, Thailand
}

\begin{abstract}
Bangkok is facing massive developments because of new transportation infrastructure. In 2012 metro lines will be constructed and connected with existing lines in order to solve traffic problems. Comparing with the first and second phase, the third phase of planning is more than challenged because some routes are designed through historic areas such as Yaowarat or Chinatown. With regard to Chinatown in Thailand, it still plays an important role in economic and traditional activities. Moreover, this area has many magnificent buildings showing historic and cultural values, which are likely to be demolished in order to construct the new modern trade buildings and subway stations. Although the new mass-transit might lead to good quality of life and convenient journeys and economic development, economic pressure will also create community relocations and evictions particularly in historic areas. To successfully drive planning processes, the big question is how to foster trust between conflicts of people. Mechanisms including many stakeholders are required to deal with different demands and solutions. This paper shows the processes and guidelines of comprising methods which bridge the gap between land owners, investors, and communities.
\end{abstract}

Keywords: ad hoc planning, distrust, transportation planning, re-mix mechanism, Bangkok.

\section{Introduction}

Among the development pressures in Bangkok in this decade, many mega projects have been planned particularly for transportation, such as subways, skytrain, trains and roads. On the one hand, Bangkok will be raising the quality of 
life by these infrastructures and the big problems in Bangkok, especially traffic jams, will be solved. On the other hand, land prices are increasing rapidly especially around subway and train stations. It is obvious that the land-use pattern near stations will be changed to commercial complex and condominiums; consequently, low- and middle- income communities are facing eviction and relocation in both areas for those routes of transportation and development involving nearby stations.

"Yaowarat", or Chinatown, in Bangkok, one of the city's historic districts, will be affected by a new subway line. The subway station will be constructed near Mongkorn Chinese Temple, one of the most important Chinese temples in Thailand. In fact, Chinatown was settled before the city of Bangkok was established in 1782. Today, the district plays an important commercial and traditional role in Thailand. Yaowarat is a node of goods distribution to the other parts of Thailand for items like souvenirs, electronic equipment, clothes and textiles, gold masters, digital products, music instruments, and importantly, traditional cultural Chinese products. In the period of the Chinese New Year 2012, the market value in Yaowarat was approximately 4 billion Baht or 114 million US dollars.

As far as the new subway line is considered, the area for Mongkorn Chinese Temple Station will affect 26 households, most of which are likely to be relocated. Moreover, more than 1,000 households around the station will face eviction and relocation depending on the scale of economic development. With little collaborative and communicative planning, situations of conflict and distrust have occurred among clients, government authorities, investors, and land owners because they could not access reliable information such as timelines of construction, cost of compensation, and especially, plans for relocation. This paper will reveal different methods and tools to deal with conflict and distrust in planning practice in the case of Chinatown in Thailand.

\section{Uncollaborative in planning practices}

Planning theory since the 1990s has begun to approach participation processes, such as collaborative planning, consensus building, and deliberative planning. It might seem that these approaches are based on values of cohesion, solidarity and inclusively could encourage interactive activities among different groups of people. Nevertheless, another side of collaborative planning such as individualist, social fragmented, and competitive, as Brand and Gaffikin [1] call "uncollaborative", appear in many contexts.

Two possible factors causing uncollaborative situations are distrustful and lazy deliberators. As far as trust and distrust are considered, it appeared in planning theory by the 2000s. Kumar and Paddison [2] and Hillier and Healey [3] explained trust in planning as a positive component of Collaborative Planning. They followed Putnam's notion [4] that trust involves reciprocity, 
serving other interests, and an ability to serve those interests. Furthermore, Kumar described eight indicators of trust:

(1) Networks of social exchange and delegation;

(2) Reciprocity and protection of one another's interests;

(3) Full and frank Information Sharing;

(4) Meeting the expectations of all partners;

(5) Expectations of desirable behaviour;

(6) No feeling of vulnerability;

(7) Control and certainty;

(8) Shares values of the stakeholders and the time factor.

Another factor causing an uncollaborative phenomenon is "lazy deliberators". As Lew Hopkins [5] highlighted, they are typically participants who do not put in extra effort. In general, urban planners try to reach consensus agreement at the end of the process. While cities have different groups of interests, it is possible that the process is not based on each common issue and interests; as a result, some groups of people are reluctant to participate. Thus, planners should encourage clients to reveal their preferences through interactive activities, but such participations are not entirely different [6].

\section{Case study}

To help solve traffic problems, the first two metro systems in Bangkok, BTS Sky Train and MRT, were launched in 1999 and 2004 respectively. In 2012, the Thai government will construct two extended lines from the initial phases. Compared with the former lines, the third phase is more challenging. One of the reasons is that the third line passes through some historic areas such as Bangkok Chinatown, called Yaowarat. One of the stations is Watmongkorn subway station which will be built near the most famous Chinese temple in Thailand. Furthermore, the surrounding area has many vital and various commercial activities, for example, Chinese traditional and custom product shops, fresh markets, Chinese and local restaurants, and street vendors.

With regards to the study area (see Figure 1), it consists of historic and modern buildings, and both reveal deterioration in their environments (see Figures 2 and 3). One possible reason behind such environment is that all buildings belong to big two landlords, such that clients have only month-bymonth leases after planning for the subway station was announced. Moreover, some have clients lived without any contracts for a long time. That is a reason why buildings and environments are ignored.

As far as the study area is concerned, it could be divided into three main groups depending on common issues and interests;

(1) Zone A: The group of the new subway station area. 26 households are dealing with eviction. Some of them are attempting to change the subway station construction area; the rest are negotiating for compensation. 
(2) Zone B: The group of historic buildings. Unfortunately, these historic buildings are not registered for conservation. Thus, those buildings can be 'regenerated' and rebuilt to be modern buildings depending on land owner desires.

(3) Zone C: The group of deteriorating apartments. Thirty years ago, the real estate company rented the land for the construction of apartment blocks. After the contract expired, the building and land were sent back to the land owner but, to date, clients have not had any leases.

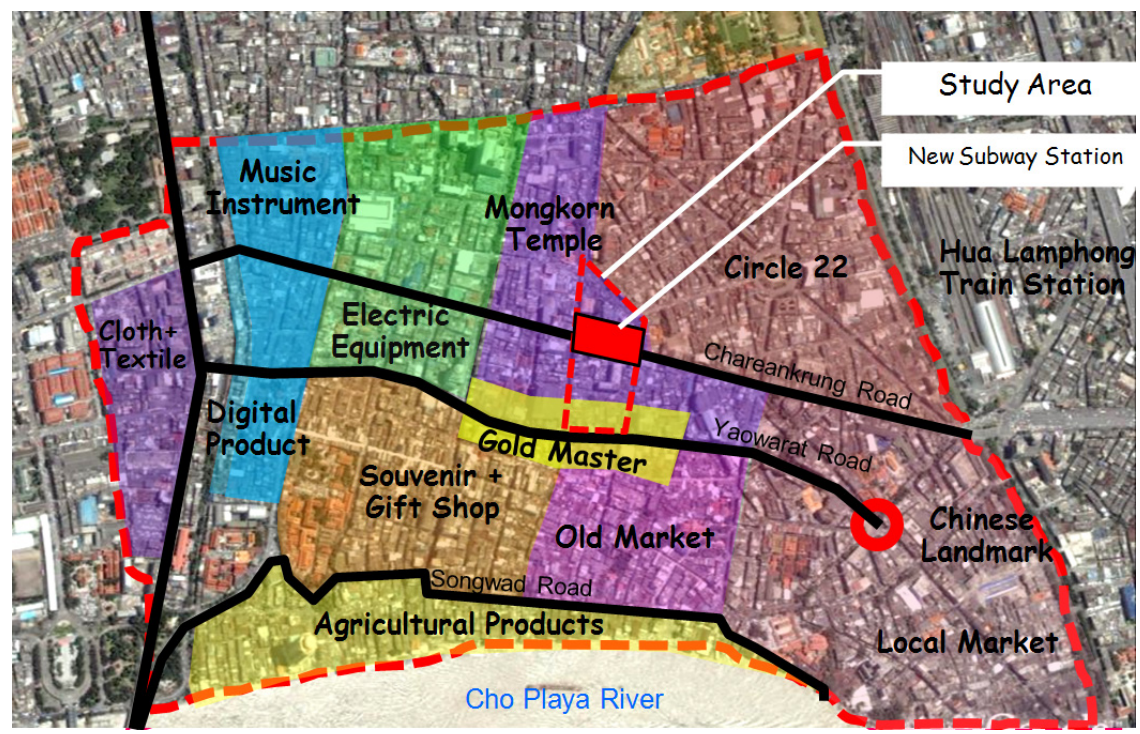

Figure 1: Districts in Yaowarat or Bangkok Chinatown and study area.

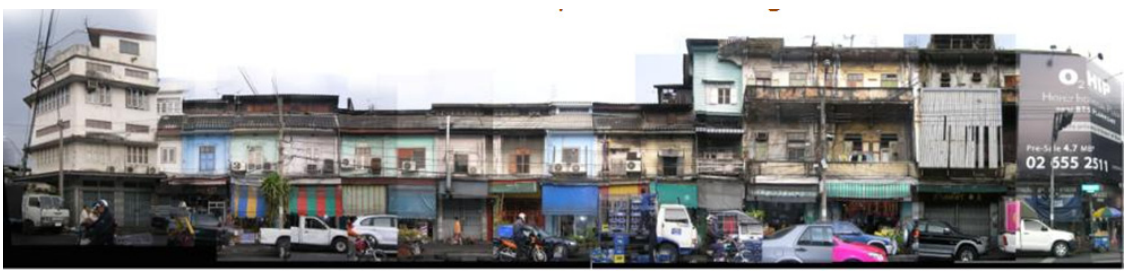

Figure 2: Historic buildings are subject to development pressure around the new subway station in Yaowarat. 


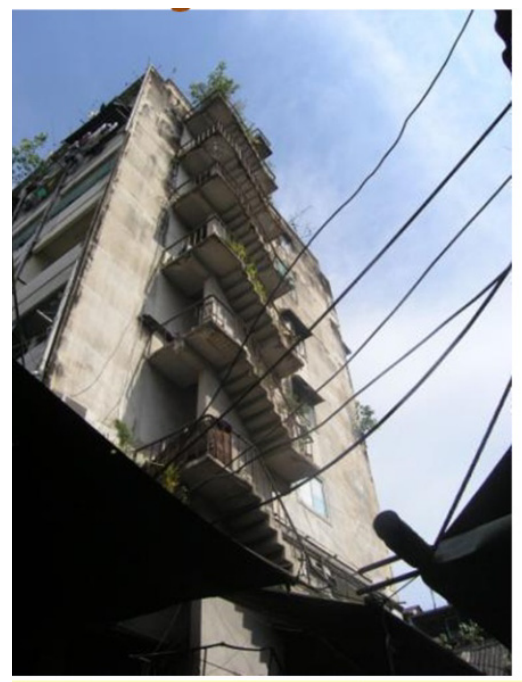

\section{Deterioration Area}

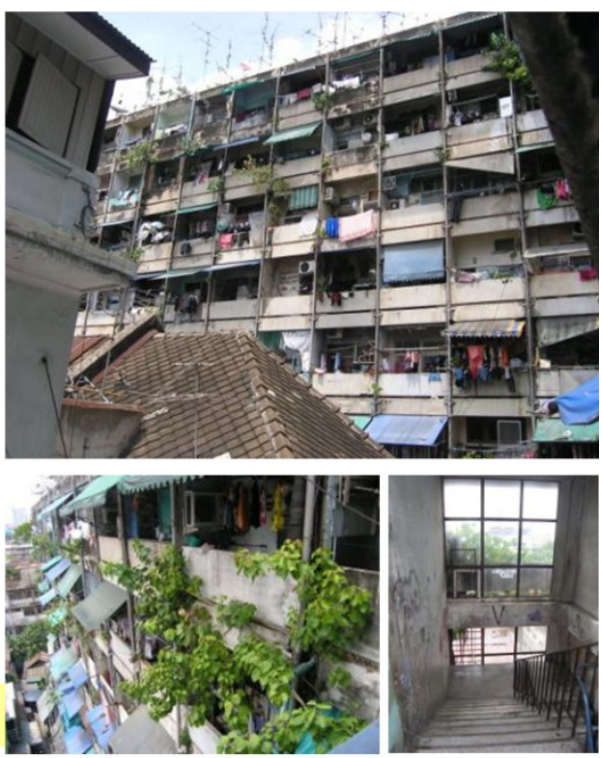

Figure 3: The deteriorating apartments, where clients have lived without any lease for a long time.

As we can see from table 1, the various groups of people have different values, problems, and, importantly, expectations. To deal with such different demands, planners need to design various tools for encouraging and driving each group to build consensus and agreement. With regard to the common problems, all of them face eviction because of the new subway station and development programme around the station. Nevertheless, their expectations are not necessarily shared. As Kaza [6] explained, planners should design the process based on different people's interests.

As Table 1 shows, the common problems can be concluded into two issues. The former is the possibility of eviction from the site of the new subway station and the development programme around the station. The latter is the lack of lease; as a result, a sense of suspicion has been heightened. Although they face the same problems, expectations are different due to the historical, environmental, economic values and capital in each area. For example, the group of the historic area attempt to promote historic value in order to conserve living places and buildings. This is, that common issues are not the only factor for designing ad hoc planning process, but also expectations should be concerned.

\section{Ad hoc planning}

In theory and law, mega projects, especially public development ones, must be discussed by different groups of stakeholders. In practice, certain information 


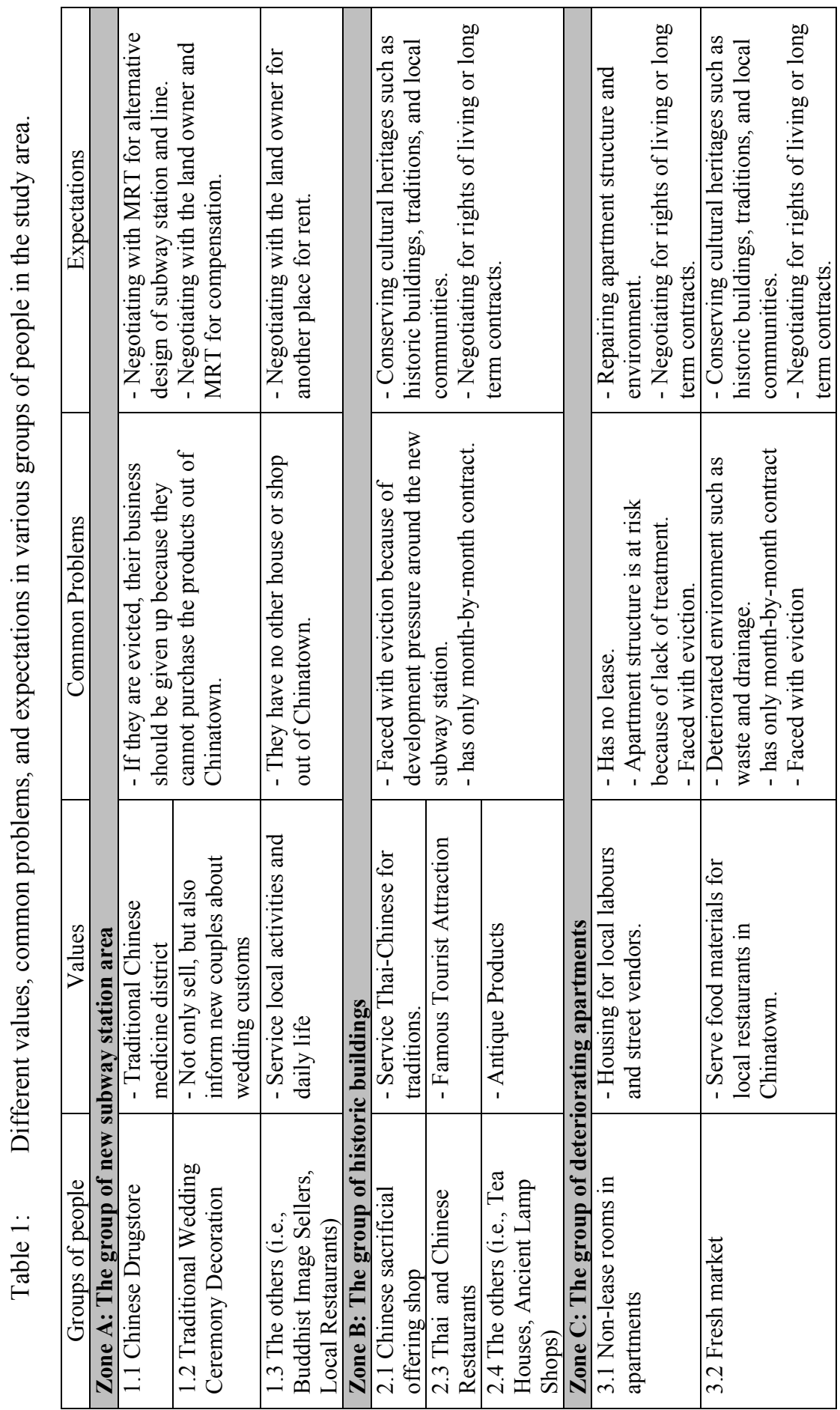


may not be distributed to clients so the distrust between authorities and clients is heightened. The clients, moreover, are suspicious of whoever is an outsider, even planners. Therefore, the first step in the planning process is not only data collecting or analysis, but also a way of gaining trust. To break the barrier of distrust, small activities and programmes are organised through children arts, mutual surveys, food heritage mappings, family history interviews, task forces, small environment improvements, and participatory design.

This dialogue research came after comprehensive transportation planning in Bangkok. Within the area there is a heightened sense of suspicion, conflict, and distrust. The research objective is how to set different platforms for dialoguing, negotiating, and discussing through experimental activities and pilot programmes. The activities had been organised simultaneously with the subway station construction. Thus, the factor of time is important. Moreover, daily conflicts and distrust are heightened by gossip. In summary, time limitation, misunderstanding, and misinterpretation are significant factors for planning practice in this context.
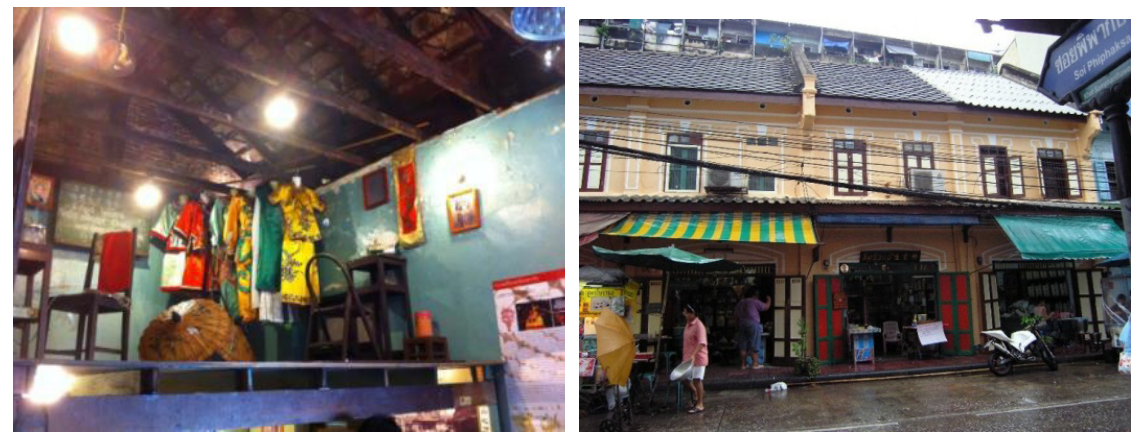

Figure 4: Small visible change examples such as the community museum (left image) and facade re-painting (right image).

As table 2 shows, ad hoc activities were deliberately designed appropriate to the different situations of conflict, distrust, and problems. For instance, the family history interview is one of the tools that can reveal individual values. Clients are comfortable and pride themselves when they are describing personal stories. The small pilot project is another confidence-building activity. The programmes, such as community museum and facade re-painting, encourage community involvement and collaborative action. Small visible change is powerful to drive the planning process among the distrust, conflict, misunderstanding, and suspicion.

\section{Conclusion and discussion}

In conflicts and confrontational contexts, comprehensive and traditional planning processes, which are progress in linear forms from data collections to solutions, are inappropriate in such social conditions. While protests, strikes, and mobs are 


\begin{tabular}{|c|c|c|c|c|c|c|c|}
\hline & 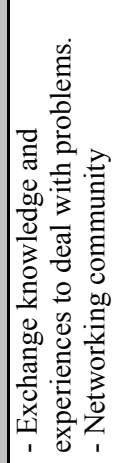 & 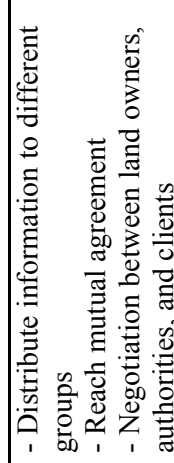 & 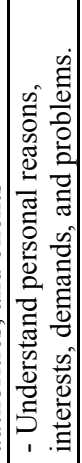 & 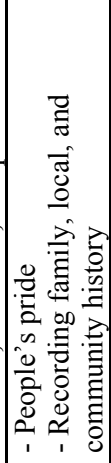 & 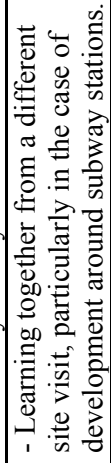 & 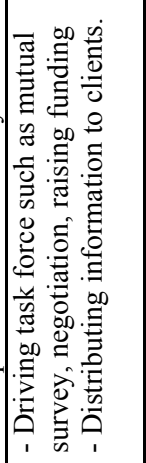 & 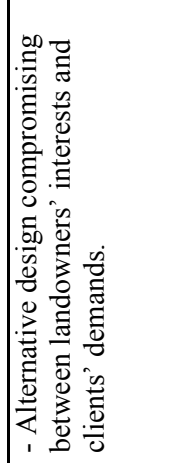 \\
\hline & 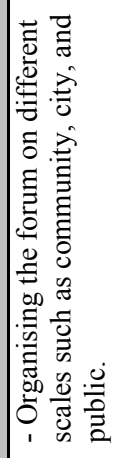 & 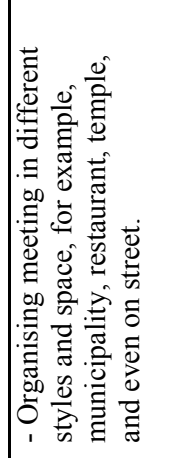 & 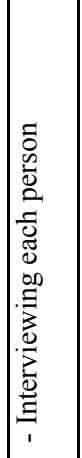 & 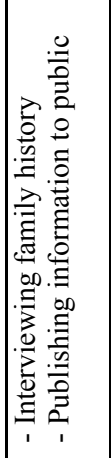 & 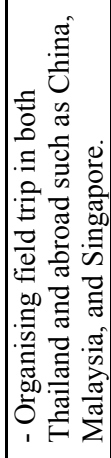 & 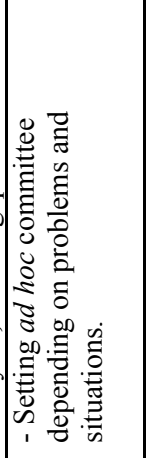 & 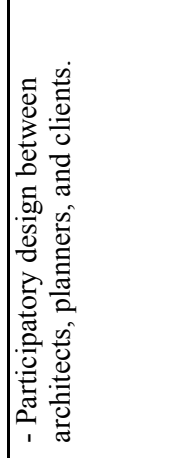 \\
\hline & 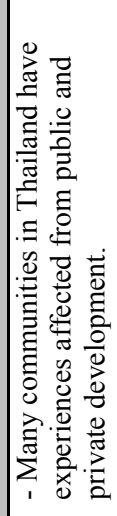 & 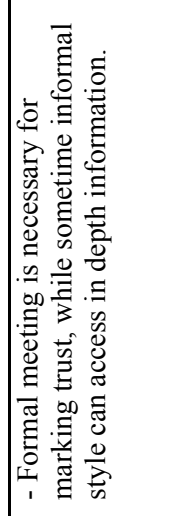 & 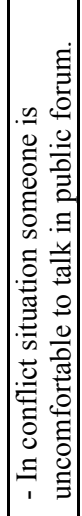 & 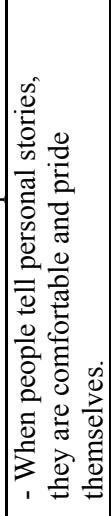 & 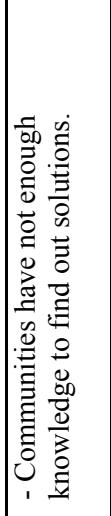 & 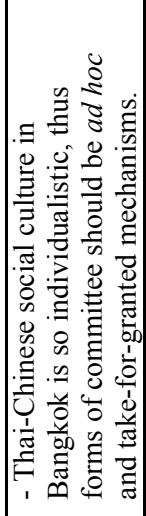 & 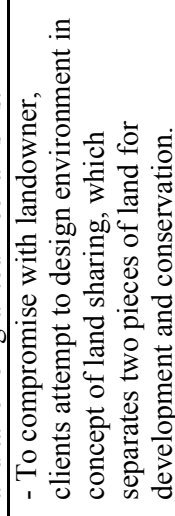 \\
\hline 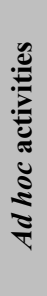 & 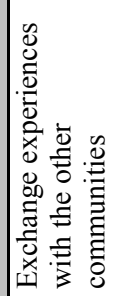 & 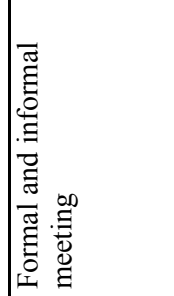 & 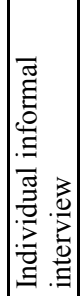 & 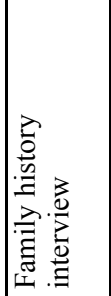 & 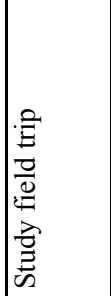 & 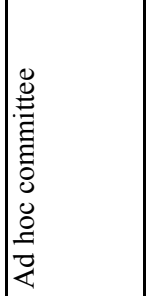 & 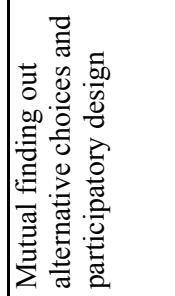 \\
\hline
\end{tabular}




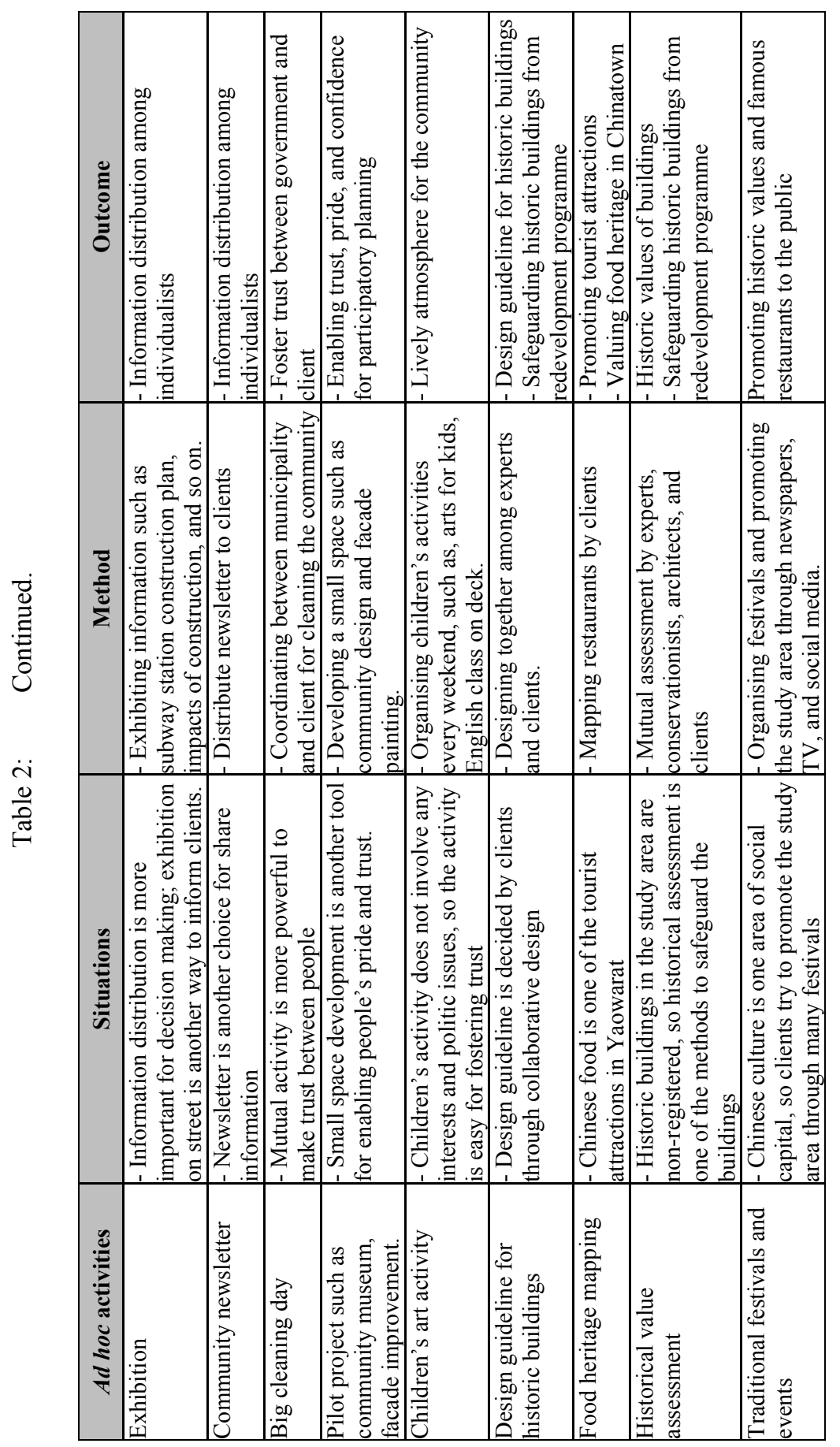




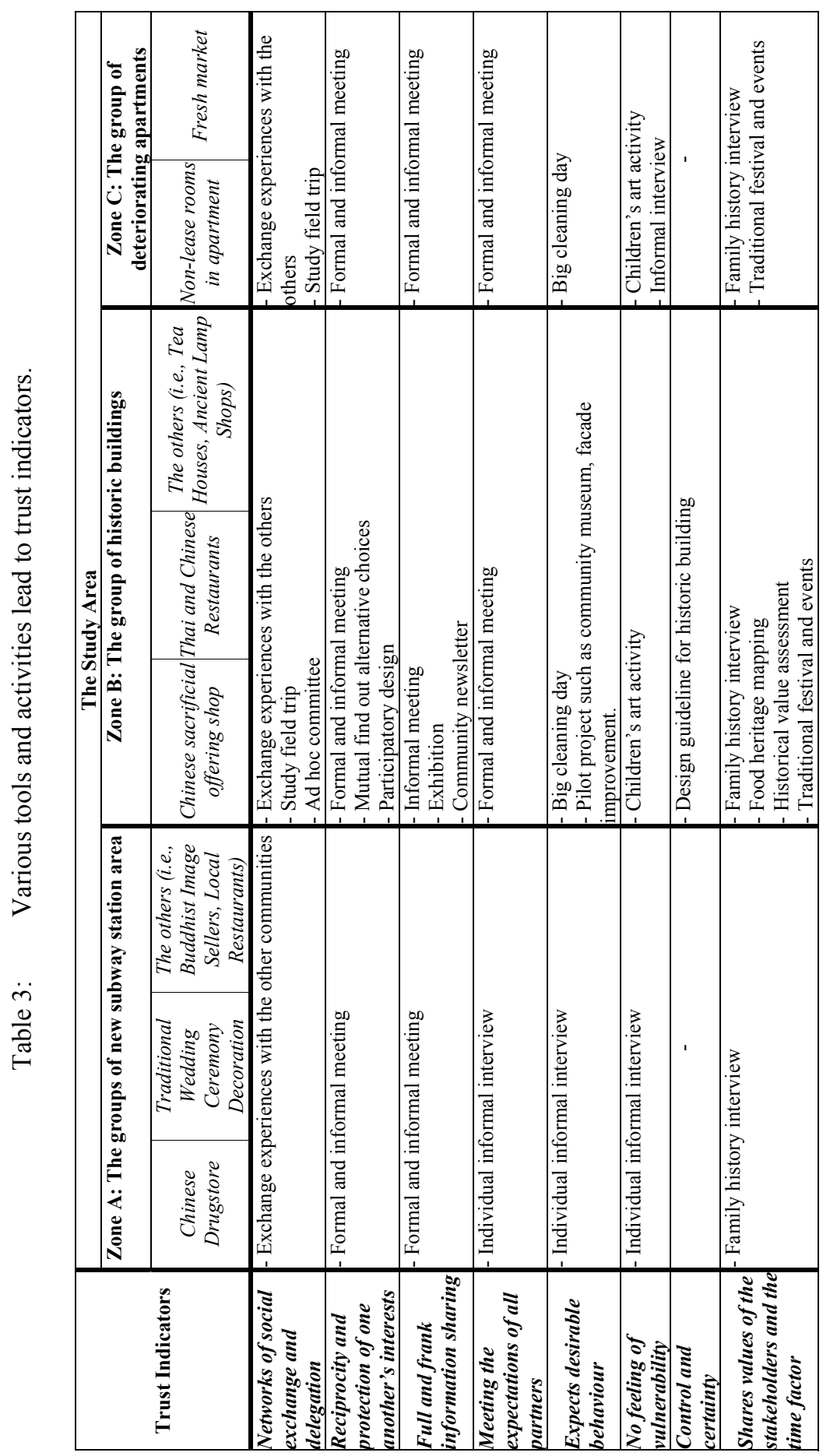

WIT Transactions on Ecology and The Environment, Vol 155, (C) 2012 WIT Press www.witpress.com, ISSN 1743-3541 (on-line) 
unpredictable situations for planners, comprehensive planning is not timely for solving problems. To deal with the conflicts, ad hoc planning based on people and sociological approaches is an alternative process that relies on small activities and programmes. Various take-for-grant activities are deliberatively organised depending on different conflicts of interests. With regard to the analysis framework for ad hoc planning, it plays more attention to social issues, such as power structures and relationships, social and cultural capital, and importantly, conflicts of interests and expectations.

As table 3 describes, various tools and activities lead to trust indicators following the Kaza concept [6]. In Zone A, the planner facilitated only formal and informal meetings and interviews because clients are more suspicious than in the other areas. One possible reason for this is because the new subway station construction was operated simultaneously to the negotiation process. Therefore, clients distrust any outsiders; even planners.

As for Zone B, social and cultural capital is material for planning, similarly Asset-Based Community Development (ABCD) [7]. Although the area was facing a development programme of a new metro station, clients and planners initiated a positive approach focusing on culture, traditions, and customs. Many significant activities are facilitated - for example, family history interviews, food heritage mapping, historical value assessment, and traditional festivals and events. Moreover, the small visible changes, including community museum and building facade re-painting, are more powerful for facilitating confidential community movement.

As far as Zone $\mathrm{C}$ is concerned, the area consists of the deteriorating apartments and fresh market. For the apartments, clients have no leases and have not paid rent for a long time. Consequently, the sense of safety and belonging has disappeared. Furthermore, environmental and building structural deterioration is a massive problem. The apartment's structure was built using an old technique that combines water pipeline with columns. Whenever the pipeline is broken, the leak will damage the structure. So, the building is at risk of collapse. In this situation, the planner organised a programme of 'big cleaning day' to encourage people to initiate repairs and reconstruction. After this, clients were more confident; they plan to reinforce the building structure and negotiate with the landowner.

Summary, ad hoc planning might be appropriate with conflict and confront situations, for example, eviction, disaster, and other unpredictable situations. Among the distrust among groups of people, information is normally distributed by gossip circles. Thus, suspicion is heightening. This is one of the contextual factors that planners should consider and design various tools that are capable of dealing with different and dynamic social contexts and situations.

\section{References}

[1] Brand, R. and Gaffikin, F., Collaborative Planning in an Uncollaborative World. Planning Theory, 6(3), pp. 282-313. 2007. 
[2] Kumar, A. and Paddison, R., Trust and Collaborative Planning Theory: The Case of the Scottish Planning System. International Planning Studies, 5(2), pp. 205-223. 2000.

[3] Hillier, J. and Healey, P., Contemporary Movements in Planning Theory: Critical Essays in Planning Theory, Volume III, Aldershot: Ashgate. pp. 78. 2008.

[4] Putnam, R. Making Democracy Work. Princeton: Princeton University Press. pp. 113. 1993.

[5] Hopkins, L. D., Urban Development: The Logic of Making Plans, Washington, DC: Island Press. pp. 97-98. 2001.

[6] Kaza, N., Tyranny of the Median and Costly Consent: A Reflection on the Justification for Participatory Urban Planning Processes. Planning Theory, 5(3), pp. 255-277. 2006.

[7] Alison, M. and Cunningham, G., From clients to citizens: Asset-based Community Development as a strategy for community-driven development. Development in Practice, 13(5), pp. 474-486. 2003. 